\title{
4. A structural investigation of the Chinese economy with a hybrid monetary policy rule
}

\author{
Jiao Wang and Ran $\mathrm{Li}^{1}$
}

\section{Introduction}

Since about 2010, China has been experiencing a gradual and persistent slowdown in gross domestic product (GDP) growth, from an average of 10 per cent over the 30 years to 2010 to the latest figure, 6.6 per cent in 2018, making the latter the slowest growth rate for three decades. Chinese President Xi Jinping described this as the 'new normal' for the Chinese economy in May 2014. The slowing of China's economic growth has attracted a great deal of attention from policymakers and scholars. The release of the official data on GDP growth often makes headline news around the world. The seemingly persistent trend of the economic slowdown triggered worries and speculation about further slowing, and even economic collapse, in the future. ${ }^{2}$ Given the increasingly important role the Chinese economy plays in the global supply chain and, in particular, in supporting demand for commodities and many intermediate goods from a number of resource-intensive economies including Australia, it is crucial to gain a better understanding of the causes of China's economic slowdown. ${ }^{3}$

What are the sources of China's economic slowdown since 2010? Researchers' answers to this question are diverse. From an international perspective, Eichengreen et al. (2012) show that rapidly growing economies slow significantly when their per capita incomes reach about US\$17,000 in year-2005 constant international purchasing power parity (PPP) prices - a level China has recently reached. Their empirical

1 We are grateful to Ippei Fujiwara, Yiping Huang, Adrian Pagan, Peter Drysdale, Paul Kitney, Ligang Song, Shiro Armstrong and two anonymous reviewers for their useful suggestions and comments at various stages of this work. We are also thankful for all the comments and questions received at the Australian Conference of Economists at the Queensland University of Technology and a seminar at the Reserve Bank of Australia. All errors are those of the authors. Jiao Wang is grateful for the financial support of the University of Melbourne Early Career Researcher (ECR) Grant Themis Agreement Number 603760.

2 A separate but related issue to the release of GDP data is the reliability of the numbers released by the National Bureau of Statistics of China. Some argue that the official numbers might have overestimated economic growth, which, if true, would make the slowdown even larger. See, for example, Fernald et al. (2013) and Chen et al. (2019) for arguments for and against, respectively, the reliability of the official data.

3 Cashin et al. (2017) estimated that a 1 per cent permanent negative GDP shock in China could lead to a 0.23 percentage point growth loss in the short run and a surge in global financial market volatility. This could translate into a fall in world economic output of 0.29 per cent overall. 
evidence from a sample including industrial and developing and emerging market economies shows that the fall in the productivity growth is the primary contributor to the economic growth slowdown, while the fall in the growth of labour share and capital investment play much smaller roles. The growth rate of human capital, on the other hand, even increased a little, so plays a positive role to economic growth (Eichengreen et al. 2012: 52-3). Cai and Lu (2013) estimate China's average annual growth potential to be 7.2 per cent over the Twelfth Five-Year Plan period and 6.1 per cent over the Thirteenth Five-Year Plan period, and highlight the diminishing demographic dividend as a result of the shrinking working-age population, which was a driver of China's rapid growth before 2010. From a business cycle perspective, there are studies that suggest that the Global Financial Crisis (GFC) was somewhat, if not solely, responsible for accelerating the slowdown process. For example, Gilchrist et al. (2009) argue that there is an evident cyclical component to Chinese growth rate dynamics and the observed slowdown since 2010 could be a temporary phenomenon tightly connected with the downswing phase of this cycle.

In this chapter, we aim to contribute to the discussion by conducting a structural investigation of the Chinese economy to better understand the sources of business fluctuations in China, especially fluctuations in output. There is, however, one puzzle that needs to be solved before we can proceed with the structural investigation. That is the unidentified rule governing China's monetary policy.

According to the Law of the People's Republic of China on the People's Bank of China, 'the objective of the monetary policy shall be to maintain stability of the value of the currency and thereby promote economic growth'. The People's Bank of China $(\mathrm{PBC})$ is by no means an inflation-targeting central bank, like many other modern central banks, and its objectives extend far beyond price stability. As former PBC governor Xiaochuan Zhou has said, China's monetary policy has the following objectives: maintaining price stability, promoting economic growth, supporting employment and achieving a balance-of-payments equilibrium (Zhou 2016). In addition, the 2017 PBC Work Conference called for monetary policy to achieve a balance between economic growth, economic reform, economic structure, household welfare and financial stability (McMahon et al. 2018). Nevertheless, there is no consensus on the form of policy rules the PBC has been employing, let alone whether such rules can achieve their objectives.

Without a well-defined monetary policy rule, it will be difficult to accurately model China's macroeconomy. The transmission mechanism of a monetary policy shock to the economy is uncertain and the effects will be difficult to predict for the central bank. What is the PBC's monetary policy rule? Has the rule changed over time? What do the data say about the monetary policy rules in practice? What are the main sources of business fluctuations in the Chinese economy given what we know about the monetary policy rules? These are the questions this chapter aims to address. 
To this end, we extend a standard new Keynesian dynamic stochastic general equilibrium (DSGE) model with financial friction shocks and investment-specific technology shocks to model the Chinese economy. The financial friction mechanism is of the type introduced by Bernanke et al. (1999) to model market imperfections in the financial sector. The investment-specific technology shock was suggested and developed by Greenwood et al. $(1988,1997)$ as a viable alternative to neutral technology shocks as sources of business cycles. Studies by Kaihatsu and Kurozumi (2014) and Justiniano et al. (2011) find that the financial friction shock and the investment-specific technology shock are important sources of business fluctuations in the United States. There are a number of studies applying DSGE models to the Chinese economy-for example, Xu and Chen (2009), Mehrotra et al. (2013), Yuan and Feng (2014) and Zhang et al. (2014). None of these studies has explicitly taken into account financial friction or shocks to investment. ${ }^{4}$ It is reasonable to expect that these factors are significant drivers of China's business fluctuations.

We propose a hybrid form of monetary policy rule for the extended model. Past studies of China's monetary policy tend to make a choice between Taylor-type rules and quantity rules that have been used in studies of advanced economies. ${ }^{5}$ For example, Zhang (2009) argues that a Taylor-type rule is likely to be more effective than a quantity-type rule in managing the economy. Liu and Zhang (2010) show that both rules outperform a single rule in a four-equation new Keynesian model. ${ }^{6}$ Since there is no consensus on the specific form of the policy rules, we incorporate a general monetary policy rule that encompasses the pure Taylor-type or quantitytype rules for estimations, and let the estimated results using real-time data show which rule best represents China's monetary policy rule.

The main findings of the chapter are as follows. First, the PBC employed a hybrid monetary policy rule during the period 2001-17, during which the policy rate was adjusted in response to the inflation rate, output, output growth as well as the growth of real money in the economy. This finding sheds light on the functional form of the real monetary policy in operation during the sample period, even though there has been no consensus on what the rule is. Furthermore, the estimations for the possible breaking point of the rule before and after 2009 show clear existence of a change in weight of the quantity component of the monetary policy rule, which could

4 Yuan et al. (2011) and Kang and Gong (2014) incorporate financial friction shocks, but not investment-specific technology shocks in their models.

5 A quantity rule for monetary policy is a rule that sets the level or growth rate of money supply in the economy, it is so named because monetary policy directly controls the quantity of money in the economy. A Taylor-type rule for monetary policy is a rule that sets the nominal interest rate of the economy. It is a price rule as it sets the price of money, the interest rate on risk-free deposits, and it is a variant of the original Taylor rule, proposed by Taylor (1993).

6 Note that Liu and Zhang (2010) use the concept of a 'hybrid rule' in their study, which means that the central bank uses both the quantity rule and the Taylor rule to conduct monetary policy. Because of the small scale of their model, this is mathematically solvable. 
be explained by the large increase in base money due to the significant fiscal and monetary stimulus after the GFC led the PBC to be more reactive to fluctuations in real money growth in the economy after 2009.

Second, the main sources of business fluctuations in output and consumption growth rates are neutral technology shocks and preference shocks, while fluctuations in investment and loans are driven primarily by investment-specific technology shocks and net-worth shocks. The structural investigation of China's business cycle shows the important contribution investment-specific technology shocks make to fluctuations in the financial sector. These investment-specific technology shocks differ from the nationwide neutral technology development shocks in affecting the economy and should be taken into account when examining economic fluctuations.

Third, while the consistently positive net-worth shocks explain the steady growth of investment, the negative neutral technology shocks have been the main contributor to the slowing of China's GDP growth since about 2010. This finding contributes to discussions of the GDP growth slowdown since that time, which has drawn huge attention from policymakers and researchers in China and among its trading partners. The finding supports the view that this phase of the slowdown is arising from a structural change in the nation's productivity, rather than a cyclical fluctuation, and policies that favour reform and industrial upgrading to address the change should be given higher priority at the leadership level.

The remainder of this chapter is organised as follows. Section two constructs the model, section three proceeds with the estimation, section four reports and discusses the results, while the concluding remarks are made in section five.

\section{The model}

The model is very close to that of Kaihastu and Kurozumi (2014), except for the central bank's behaviour. In this section, we will describe the behaviour of each agent in the economy in detail while presenting only a few mathematical equations. For details of system equations and derivations of optimal conditions, please see the working paper version of this chapter (Li and Wang 2018).

There are households comprising worker and entrepreneur members, financial intermediaries, intermediate-goods firms, consumption-goods firms, investmentgoods firms, capital-goods firms and the central bank in the economy. The financial accelerator mechanism of Bernanke et al. (1999) is employed in the financial sector. The economy is subject to both technology shocks and financial shocks. 
The representative household comprises a continuum of members normalised to unity. A proportion of members are workers, denoted by $m \in[0,1]$, and the rest are entrepreneurs. All members are assumed to pool their consumption and make joint consumption-saving decisions. The representative household's utility function consists of aggregate consumption with external habit formation-that is, previous aggregate consumption enters the utility function as an external inertia to the current consumption level, which smooths the effect of consumption on the utility of the representative households. Real money balance and labour efforts enter the utility function as standard in the DSGE model literature. The representative household consumes, works and saves via the financial intermediaries, which will be introduced shortly, receives dividends from firms that they own and pays taxes to the government. They also receive money transfers from the central bank in each period.

Workers - the designated proportion of household members-receive wages for working for production firms. The labour market is monopolistically competitivethat is, firms pay a markup above the base wage that measures the marginal productivity of workers. In the meantime, we assume that wages adjust sluggishly, according to a Calvo (1983) adjustment rule. In each period, a fraction of $1-\xi_{m} \in$ $(0,1)$ of workers are able to reoptimise their wages, while the wages of the remaining fraction, $\xi_{m}$, of workers are set by indexation to past inflation as well as the steadystate balanced growth rate, $z^{*}$.

Entrepreneurs - the remaining household members-enter period $t$ with net worth, $N_{t-1}$, left from the previous period and obtain a loan, $L_{t-1}$, from financial intermediaries. They purchase capital, $K_{t-1}$, from capital-goods firms at a given price, $Q_{t-1}$, and choose the capital utilisation rate, $\mu_{t}$. They then provide rental capital services to intermediate-goods firms and sell the rest of their capital back to capital-goods firms. After repaying their loan to the financial intermediary, a fraction, $1-\eta_{t} \in(0,1)$, of entrepreneurs become workers, while the remaining, $\eta_{t}$, survive into the next period. This assumption is to ensure the relative population size of workers and entrepreneurs remains constant over time.

The loan rate, $E_{t} r_{t+1}^{E}$, consists of a deposit rate and the external finance (EF) premium, in the spirit of Bernanke et al. (1999) as Equation 4.1.

\section{Equation 4.1}

$E_{t} r_{t+1}^{E}=E_{t}\left(\frac{r_{t}^{n}}{\pi_{t+1}}\right) F\left(\frac{Q_{t} K_{t}}{N_{t}}\right) \exp \left(z_{t}^{\mu}\right)$

It shows that the loan rate is increasing with the leverage ratio and decreasing with the net worth of the debtor. 
The intermediate-goods firms and consumption-goods firms follow the standard assumption and settings in DSGE models. Briefly, each intermediate-goods firm produces output according to nationwide technology with capital rented from entrepreneurs and the labour efforts of workers. The output is then sold in a monopolistically competitive market to consumption-goods firms. The price of the intermediate goods is again subject to the Calvo (1983) adjustment rule. Consumption-goods firms bundle the intermediate goods without cost into the final consumption goods for the households to consume. The price of the final goods is the consumer price index (CPI).

There are two other types of firms in the economy that are involved in capital-related production: investment-goods firms and capital-goods firms. The former convert one unit of consumption goods into differentiated investment goods according to an investment-specific technology, $\Psi_{t}$, which is a different technology from the intermediate-goods production technology, $Z_{i}$. The capital-goods firm takes the price of the investment goods and chooses an optimal combination of investment goods from all the investment-goods firms.

The central bank in the model is assumed to conduct monetary policy according to the rule proposed in Equation 4.2.

\section{Equation 4.2}

$$
\begin{aligned}
\log \left(r_{t}^{n}\right)=W( & -\log \left(1-\frac{1}{\lambda_{t}} \exp \left(z_{t}^{b}\right) \exp \left(z_{t}^{m}\right) m_{t}^{-\sigma}\right. \\
& +(1-W)\left(\phi_{r} \log \left(r_{t-1}^{n}\right)+\left(1-\phi_{r}\right)\left(\log \left(r^{n}\right)\right.\right. \\
& +\frac{\phi_{\pi}}{4} \sum \log \left(\frac{\pi_{t-j}}{\pi}\right)+\phi_{y} \log \left(\frac{\frac{Y_{t}}{Z_{t}^{*}}}{y}\right) \\
& +\phi_{d y} \log \left(\frac{\frac{Y_{t}}{Y_{t-1}}}{z^{*}}\right)+z_{t}^{r}
\end{aligned}
$$

This functional form consists of a linear combination of the part related to real money demand from the household, represented by the bracket associated with $W$ and the part related to a typical Taylor rule, represented by the bracket associated with $(1-W)$, and an exogenous shock, $z_{t}^{r}$. Setting the monetary policy rule in the above form allows us to feed the model with real-time Chinese data to obtain estimates of $W$. If $W=1$, the above rule collapses to the condition describing the optimal demand for real money supply, which then determines the interest rate given $m t$. If $W=0$, the above rule reduces to a typical Taylor-type rule with the interest rate responding to inflation and economic output. Finally, if $0<W<1$, the rule tells us that the policy rate responds to real money as well as inflation and economic output. We call the rule 
in this case a 'hybrid rule'. To close the model, we need another condition for the money supply in the economy. We follow Christiano et al. (2005) and define money growth following an $\mathrm{AR}(1)$ process, as in Equation 4.3.

Equation 4.3

$M_{t}^{s}=\mu_{t} M_{t-1}^{s}$ and $\log \left(\mu_{t}\right)=\log \left(\mu_{0}\right)+z_{t}^{m g}$

\section{Estimation}

We adopt a Bayesian likelihood approach from Kaihastu and Kurozumi (2014) with 12 Chinese quarterly time series: output, consumption, investment, labour (hours worked), the real wage, the price of consumption goods, the relative price of investment goods, the monetary policy rate, the loan rate, real loans, real net worth and real money balances. The data are obtained from the CEIC China Premium Database and the sample period is 2001-17 at quarterly frequency. Details of the sources of these data series are in the working paper version of this chapter ( $\mathrm{Li}$ and Wang 2018).

Before taking the model to the estimation, a detrending of equilibrium conditions is needed since we allow for non-stationary technology in the economy. The stationary system is then log-linearised around its deterministic steady state with a capital utilisation rate of unity. We follow Smets and Wouters (2007) and Kaihastu and Kurozumi (2014) and use the Kalman filter to evaluate the likelihood function for the log-linear system and apply the Metropolis-Hastings algorithm to generate draws from the posterior distribution of model parameters. ${ }^{7}$

There are two sets of parameters: one to be estimated and the other calibrated to avoid any identification issues. To save space here, we do not present the table with calibration. The prior distribution of the 49 parameters to be estimated and the posterior estimates are reported in Table A4.1. Detailed discussions about the calibrated values and choices of prior distributions are in the working paper version of this chapter (Li and Wang 2018).

7 Our estimation is done using Dynare (Adjemian et al. 2011). In each estimation, 200,000 draws were generated, the first half of which were discarded. The scale factor for the jumping distribution in the Metropolis-Hastings algorithm was adjusted so that an acceptance rate of about 24 per cent was obtained. 


\section{Results}

In this section, we present the results in three main parts. The first part reports the statistics of the posterior mean estimates of parameters over the sample period 2001Q1 - 2017Q4. A possible change of policy rule is also considered in this part. The second part of the section presents variance decompositions of output, consumption, investment and loans based on the estimated model. Both forecast error variance decompositions and historical decompositions are reported. Through this exercise, we are able to answer some fundamental questions about the main sources of economic fluctuations in China. The final part presents some discussions of the results.

\section{Estimates of monetary policy rule}

The first row of Table A4.1 reports the posterior mean of $W$ and the 90 per cent confidence interval. Over the full sample period, $W$ is estimated to be 0.0911 and is statistically significant from zero. Given the estimated value, the monetary policy rule in Equation 4.1 is indeed a hybrid rule. Over the past decade or more, the PBC conducted monetary policy by adjusting the policy rate according to the real money level, inflation rate, output level and output growth in the economy with assigned weights. Other macroeconomic conditions were subsequently pinned down through the interest rate channel in equilibrium. This finding could serve as a benchmark approach for estimating China's monetary policy rules as macro and financial conditions in China evolve over time.

We also conduct subsample estimations searching for possible policy rule changes. During the sample period, there was a breakdown of the global financial system, which might have caused some policy changes in the PBC. Recently, PBC officials have made several public speeches discussing the necessity of reforming monetary policy towards more price tool-based practices. We set 2009Q1 as the potential change point and estimate the model over the two subsamples. The results are reported in Tables A4.2 and A4.3. They show that the mean estimates of $W$ are statistically and significantly different from each other before and after the breaking point in 2009Q1. Specifically, the posterior mean of $W$ before 2009Q1 is equal to 0.0859 , while after 2009Q1, it increases to 0.2466 — both of which are statistically different from zero. ${ }^{8}$

This finding deserves some discussion. The different weights attached to the quantity part of the monetary policy rule before and after 2009 indicate that the GFC had a measurable impact on China's monetary policy. Despite the public speeches by

8 As a sensitivity check, we also use 2008Q1 and 2007Q1 as a potential breaking point for subsample estimations, and we obtain similar results to those using 2009Q1 as the breaking point. 
PBC officials about moving towards more price tool-based practices, the actual monetary policy rule still places more weight on the quantity movements of real money balance in the economy. This is very likely considering the large fiscal and monetary stimulus that was put in place after the GFC. The PBC was aware of the increase in the money base in the economy and responded to a larger extent to the quantity component of the policy rule, everything else being equal, after the onset of the financial crisis.

\section{Variance decompositions}

Given the estimated monetary policy rule in the previous subsection, we can proceed with the investigation of the business cycle fluctuations in the Chinese economy in the period 2001-17. To see what accounts for the fluctuations in the key macroeconomic variables, we present the forecast error decompositions of the variances of output, consumption, investment and loans in Table A4.4 and historical decompositions of output and investment in Figures A4.1 and A4.2 based on the estimated model.

Table A4.4 shows the relative contribution of each shock to the variations in output growth, consumption growth, investment growth and real loan growth at forecast horizons $\mathrm{T}=8,32$ quarters, evaluated at the posterior mean estimates of parameters. The main source of the output fluctuation is the exogenous demand shock. The next two important sources are the neutral technology shock and the preference shock. The investment-specific technology shock makes a small but increasing contribution to the output fluctuation from short-term ( 6 per cent) to long-term (11 per cent) horizons. The remainder of the shocks are negligible. The preference shock is the dominant source of the fluctuation in consumption, making up nearly 70 per cent of the variation. The neutral technology shock is the secondary source, while the remaining shocks all play minor roles. Half of the variation in investment growth is explained by the investment-specific shock, while 26 per cent is explained by the net-worth shock in the short run. The investment-specific shock becomes even more prominent in the long run (61 per cent). The intermediate-goods markup also plays a small role in affecting investment activities. The investment-specific and net-worth shocks also play a primary and secondary role, respectively, in explaining the fluctuations in real loans. The shock to the marginal efficiency of investment contributes marginally to the loan variation.

The results above reveal the main sources of business fluctuation in China. The real sectors - that is, consumption-goods sectors - are driven primarily by the neutral technology, preference and external demand shocks, while the financial sectors are dominated by the investment-specific technology and net-worth shocks. 
To get a closer look at the fundamentals of business fluctuations in China, we present the historical decompositions of the percentage point deviations of output and investment from their respective steady states in Figures A4.1 and A4.2. Figure A4.1 shows a steadily decreasing trend of output growth from about 2011, with the neutral technology shock as the main negative contributor. This suggests that a structural break in neutral technological development-from consistently positive in 2001-07 to consistently negative in 2010-17- has been the primary driver of the slowing of China's GDP growth since 2010 that we discussed at the beginning of the chapter. There is a drastic fall in output growth from about mid2008 to early 2009 in Figure A4.1. This corresponds to the onset of the GFC. The sudden meltdown of the global financial system and then of the real economy may affect technology and production through trade and financial channels.

Figure A4.2 shows that investment growth is, on average, positive and the networth shock is the primary positive contributor. Investment-specific technology is another key factor, but its contribution is volatile. This means that growth in investment is driven by the positive valuation of net worth while the volatility of investment is driven by its own technological development. Looking forward, we should be cautious about whether these valuation effects on net worth can continue and carefully monitor the evolution of investment activities.

Figures A4.1 and A4.2 together bring us another perspective on China's growth story: investment was steadily growing while economic growth showed clear signs of slowing over the past decade.

\section{Discussions}

Before closing this section, we would like to discuss the usefulness of the extended DSGE model we have used in this chapter and policy implications based on the results obtained. First, financial friction is indispensable in the model. We incorporate financial intermediaries and financial friction into the model as we expect them to be important sources of business fluctuations in China, as they are in the United States. The posterior mean estimation of the elasticity of the external finance premium (that is, $\mu$ in Table A4.1) shows that this premium equation is statistically significant in the model. The important role of the net-worth shock in explaining investment fluctuations also proves this point.

Second, we specify neutral technology and investment-specific technology as two types of technology for the consumption-goods sector and investment-goods sector. As demonstrated in the previous section, neutral technology is one of the main drivers of output growth fluctuations, while investment-specific technology and 
net-worth technology are the main drivers of investment activities. Without the specification of the two types of technologies, we would obtain misleading results of the main sources of business fluctuations in China.

Third, a hybrid monetary policy rule is obtained by constructing a generalised form of rule without imposing ex ante model restrictions and employing a Bayesian estimation strategy using real Chinese data. This approach can serve as a benchmark for future researchers to estimate China's monetary policy rule as macroeconomic and financial conditions evolve over time.

Last but not the least, the finding that negative development in neutral technology since about 2010 contributed to output variation provides important policy implications. As discussed in the introduction of the chapter, there are numerous explanations about the recent economic output slowdown without any consensus on the fundamental factors. Our result is supportive of the argument that it is mainly the technological slowdown that contributed to output fluctuations. Policies supporting technological innovations and industrial upgrading are then favourable in addressing such negative technological development. The 'new normal' of the Chinese economy would be sustainable if the future economic growth is supported by new industries and innovations in new and upgraded technology.

\section{Conclusions}

Policymakers and scholars are increasingly concerned with the recent economic slowdown in China. Our findings show that negative neutral technology development is what has caused this output fluctuation. After more than 30 years of driving high-speed economic development, the growth potential of neutral technological advancement has shown a clear sign of slowing. This has the important policy implication of encouraging technological innovation and industrial upgrading in China.

We construct a rich DSGE model in this chapter for the structural investigation of the Chinese economy. The results show that it captures important features of the economy that have not been found in previous studies using a simple model. Importantly, we find that China's monetary policy rule is a hybrid one. China's central bank conducts monetary policy by adjusting the policy rate in response to inflation, output conditions and real money growth. The policy rule changed after about 2009 towards placing more weight on responding to movements in the real money balance compared with before 2009. This suggests the quantity of money is strongly affecting monetary policy practices. 
The variance decompositions of the key variables show the relative importance of various shocks in explaining the fluctuations of those variables. Specifically, financial friction shocks are indispensable sources of investment fluctuation. Neutral technology development was a consistently positive contributor to output growth during the period 2001-07 and became a negative contributor after 2010 . This finding provides further evidence of the sources of the GDP slowdown in China since about 2010, pointing out that technological development has played a significant role in dragging down the pace of productivity growth. Future work on the causes of business fluctuations in China and China's monetary policy rule can draw on the results in this chapter.

\section{References}

Adjemian, S., Bastani, H., Juillard, M., Mihoubi, F., Perendia, G., Ratto, M. and Villemot, S. (2011), Dynare: Reference Manual Version 4, Dynare Working Papers 1, Paris: CEPREMAP.

Bernanke, B.S., Gertler, M. and Gilchrist, S. (1999), The financial accelerator in a quantitative business cycle framework, in J.B. Taylor and M. Woodford (eds), Handbook of Macroeconomics: Volume 1A, Amsterdam: Elsevier. doi.org/10.1016/S15740048(99)10034-X.

Cai, F. and Lu, Y. (2013), Population change and resulting slowdown in potential GDP growth in China, China \& World Economy 21: 1-14. doi.org/10.1111/j.1749-124X. 2013.12012.x.

Calvo, G.A. (1983), Staggered prices in a utility-maximizing framework. Journal of Monetary Economics 12(3): 383-98.

Cashin, P., Mohaddes, K. and Raissi, M. (2017), China's slowdown and global financial market volatility: Is world growth losing out?, Emerging Markets Review 31: 164-75. doi.org/10.1016/j.ememar.2017.05.001.

Chen, W., Chen, X., Hsieh, C.-T. and Song, Z.M. (2019), A forensic examination of China's national accounts, Brookings Papers on Economic Activity, Spring, Washington, DC: Brookings Institution. doi.org/10.3386/w25754.

Christiano, L.J., Eichenbaum, M. and Evans, C.L. (2005), Nominal rigidities and the dynamic effects of a shock to monetary policy, Journal of Political Economy 113: 1-45. doi.org/10.1086/426038.

Christiano, L.J., Motto, R. and Rostagno, M. (2010), Financial factors in economic fluctuations, ECB Working Paper No. 1192, Frankfurt am Main: European Central Bank.

Eichengreen, B., Park, D. and Shin, K. (2012), When fast-growing economies slow down: International evidence and implications for China, Asian Economic Papers 11: 42-87. doi.org/10.1162/ASEP_a_00118. 
Fernald, J., Malkin, I. and Spiegel, M. (2013), On the reliability of Chinese output figures, Federal Reserve Bank of San Francisco Economic Letter 8: 1-5.

Gilchrist, S., Ortiz, A. and Zakrajsek, E. (2009), Credit risk and the macroeconomy: Evidence from an estimated DSGE model, 27 July, available from: ssrn.com/abstract=2088909.

Greenwood, J., Hercowitz, Z. and Huffman, G.W. (1988), Investment, capacity utilization, and the real business cycle, The American Economic Review 78(3): 402-17.

Greenwood, J., Hercowitz, Z. and Krusell, P. (1997), Long-run implications of investmentspecific technological change, The American Economic Review 87(3): 342-62.

Justiniano, A., Primiceri, G.E. and Tambalotti, A. (2011), Investment shocks and the relative price of investment, Review of Economic Dynamics 14: 102-21. doi.org/10.1016/j.red. 2010.08.004.

Kaihatsu, S. and Kurozumi, T. (2014), Sources of business fluctuations: Financial or technology shocks?, Review of Economic Dynamics 17: 224-42. doi.org/10.1016/j.red. 2013.08.001.

Kang, L. and Gong, L. (2014), Financial frictions, net worth of bank and transmission of international crisis: Based on multi-sector DSGE model analysis, Economic Research Journal 49: 147-59.

Li, R. and Wang, J. (2018), A structural investigation of the Chinese economy with a hybrid rule, University of Melbourne, Mimeo, 2018.

Liu, L.-G. and Zhang, W. (2010), A new Keynesian model for analysing monetary policy in mainland China, Journal of Asian Economics 21: 540-51. doi.org/10.1016/ j.asieco.2010.07.004.

McMahon, M., Schipke, A. and Li, X. (2018), China's monetary policy communication: Frameworks, impact, and recommendations, IMF Working Paper No. WP/18/244.

Mehrotra, A., Nuutilainen, R. and Pääkkönen, J. (2013), Changing economic structures and impacts of shocks: Evidence from a dynamic stochastic general equilibrium model for China, Pacific Economic Review 18: 92-107. doi.org/10.1111/1468-0106.12012.

Smets, F. and Wouters, R. (2007), Shocks and frictions in US business cycles: A Bayesian DSGE approach, American Economic Review 97(3): 586-606.

Sun, L. and Sen, S. (2011), Monetary policy rules and business cycle in China: Bayesian DSGE model simulation, 9 April. doi.org/10.2139/ssrn.1806347.

Taylor, J.B. (1993), Discretion versus policy rules in practice, Carnegie-Rochester Conference Series on Public Policy 39: 195-214, North-Holland.

Wang, G. and Tian, G. (2014), Financial shocks and Chinese business cycle, Economic Research Journal 49: 20-34.

Xu, W. and Chen, B. (2009), Bank lending and economic fluctuations in China: 1993-2005, China Economic Quarterly 8: 969-94. 
Yuan, P. and Feng, L. (2014), Research of housing price rise effects based on DSGE: Economic growth, income distribution and wealth gap widening, Economic Research Journal 49: 77-90.

Yuan, S., Chen, P. and Liu, L. (2011), Exchange rate system, financial accelerator and economical undulation, Economic Research Journal 2011-01: 57-70.

Zhang, W. (2009), China's monetary policy: Quantity versus price rules, Journal of Macroeconomics 31: 473-84. doi.org/10.1016/j.jmacro.2008.09.003.

Zhang, W., Zheng, J. and Huang, Y. (2014), An analysis on anticipated shocks of monetary policy and industrial transmission: Based on a multi-sectoral DSGE model, Journal of Financial Research: 33-49.

Zhou, X.C. (2016), Managing multi-objective monetary policy: From the perspective of transitioning Chinese economy, The 2016 Michel Camdessus Central Banking Lecture, 24 June, International Monetary Fund, Washington, DC.

\section{Appendix A}

Table A4.1 Prior and posterior distributions of parameters - full sample

\begin{tabular}{|l|r|r|r|r|r|r|}
\hline & Prior mean & Post mean & \multicolumn{2}{l|}{$90 \%$ HPD interval } & \multicolumn{1}{l|}{ Prior } & \multicolumn{1}{c|}{ Pstdev } \\
\hline alpha & 0.500 & 0.0911 & 0.0179 & 0.1686 & unif & 0.2887 \\
\hline Csigma & 2.000 & 0.8737 & 0.5647 & 1.1324 & gamma & 0.3750 \\
\hline Ctheta & 0.700 & 0.5582 & 0.4176 & 0.6862 & beta & 0.1000 \\
\hline cchi & 2.000 & 2.6598 & 1.5509 & 3.7217 & gamma & 0.7500 \\
\hline czeta & 4.000 & 3.3357 & 2.2265 & 4.5573 & gamma & 1.5000 \\
\hline ctau & 0.220 & 0.3155 & 0.1080 & 0.5033 & gamma & 0.1000 \\
\hline cphi & 0.250 & 0.0531 & 0.0052 & 0.0986 & beta & 0.1250 \\
\hline calpha & 0.600 & 0.1440 & 0.0860 & 0.2020 & beta & 0.1000 \\
\hline gammaw & 0.500 & 0.2471 & 0.1017 & 0.3878 & beta & 0.1500 \\
\hline xiw & 0.500 & 0.6422 & 0.5621 & 0.7186 & beta & 0.1000 \\
\hline gammap & 0.500 & 0.3213 & 0.1461 & 0.4882 & beta & 0.1500 \\
\hline xip & 0.500 & 0.8075 & 0.7412 & 0.8664 & beta & 0.1000 \\
\hline phir & 0.750 & 0.7664 & 0.6873 & 0.8412 & beta & 0.1000 \\
\hline phipi & 1.500 & 1.7688 & 1.3955 & 2.1307 & gamma & 0.2500 \\
\hline phiy & 0.125 & 0.0440 & 0.0201 & 0.0681 & gamma & 0.0500 \\
\hline phidy & 0.125 & 0.0579 & 0.0267 & 0.0869 & gamma & 0.0500 \\
\hline zstarss & 1.163 & 1.2187 & 1.0790 & 1.3613 & gamma & 0.1000 \\
\hline psiss & 0.077 & 0.0672 & 0.0144 & 0.1195 & gamma & 0.0400 \\
\hline hss & -0.1304 & -2.4195 & 2.3909 & norm & 2.0000 \\
\hline piss & 0.2660 & 0.1459 & 0.3955 & gamma & 0.1000 \\
\hline
\end{tabular}


4. A structural investigation of the Chinese economy with a hybrid monetary policy rule

\begin{tabular}{|l|r|r|r|r|r|r|}
\hline & Prior mean & Post mean & \multicolumn{2}{|c|}{$90 \%$ HPD interval } & Prior & \multicolumn{1}{|c|}{ Pstdev } \\
\hline rnss & 1.030 & 1.1060 & 0.9655 & 1.2442 & gamma & 0.1000 \\
\hline eta & 0.973 & 0.9552 & 0.9276 & 0.9838 & beta & 0.0200 \\
\hline nkss & 0.500 & 0.6077 & 0.5089 & 0.7027 & beta & 0.0700 \\
\hline cmu & 0.070 & 0.0203 & 0.0141 & 0.0271 & gamma & 0.0200 \\
\hline ress & 1.242 & 1.2177 & 1.1374 & 1.2929 & gamma & 0.0500 \\
\hline rho_b & 0.500 & 0.7916 & 0.6060 & 0.9558 & beta & 0.2000 \\
\hline rho_g & 0.500 & 0.9707 & 0.9470 & 0.9944 & beta & 0.2000 \\
\hline rho_w & 0.500 & 0.2055 & 0.0349 & 0.3726 & beta & 0.2000 \\
\hline rho_p & 0.500 & 0.9039 & 0.8407 & 0.9774 & beta & 0.2000 \\
\hline rho_i & 0.500 & 0.8897 & 0.8323 & 0.9448 & beta & 0.2000 \\
\hline rho_r & 0.500 & 0.2256 & 0.0632 & 0.3813 & beta & 0.2000 \\
\hline rho_z & 0.500 & 0.1307 & 0.0295 & 0.2226 & beta & 0.2000 \\
\hline rho_psi & 0.500 & 0.9568 & 0.9249 & 0.9909 & beta & 0.2000 \\
\hline rho_nu & 0.500 & 0.9850 & 0.9774 & 0.9924 & beta & 0.2000 \\
\hline rho_mu & 0.500 & 0.5413 & 0.4254 & 0.6784 & beta & 0.2000 \\
\hline rho_eta & 0.500 & 0.8246 & 0.7015 & 0.9634 & beta & 0.2000 \\
\hline rho_mg & 0.500 & 0.3782 & 0.1867 & 0.5541 & beta & 0.2000 \\
\hline e_b & 0.500 & 2.8286 & 1.5204 & 3.8269 & invg & Inf \\
\hline e_g & 0.500 & 0.8964 & 0.7581 & 1.0319 & invg & Inf \\
\hline e_w & 0.500 & 0.4458 & 0.3527 & 0.5515 & invg & Inf \\
\hline e_p & 0.500 & 0.1624 & 0.1037 & 0.2165 & invg & Inf \\
\hline e_i & 0.500 & 1.1037 & 0.9333 & 1.2754 & invg & Inf \\
\hline e_r & 0.500 & 0.1287 & 0.1088 & 0.1467 & invg & Inf \\
\hline e_z & 0.500 & 1.7636 & 1.4635 & 2.0584 & invg & Inf \\
\hline e_psi & 0.500 & 0.3763 & 0.2735 & 0.4741 & invg & Inf \\
\hline e_nu & 0.500 & 4.1778 & 3.3739 & 4.9908 & invg & Inf \\
\hline e_mu & 0.500 & 0.2854 & 0.2462 & 0.3230 & invg & Inf \\
\hline e_eta & 0.500 & 0.8999 & 0.5881 & 1.2119 & invg & Inf \\
\hline e_mg & 0.500 & 0.5839 & 0.5022 & 0.6575 & invg & Inf \\
\hline
\end{tabular}

Note: Alpha is the weight on quantity rule.

Table A4.2 Prior and posterior distributions of parameters - subsample: before 2009Q1

\begin{tabular}{|l|r|r|r|r|r|r|}
\hline & Prior mean & Post mean & \multicolumn{2}{c|}{$90 \%$ HPD interval } & \multicolumn{1}{c|}{ Prior } & \multicolumn{1}{c|}{ Pstdev } \\
\hline alpha & 0.500 & 0.0859 & 0.0005 & 0.1753 & unif & 0.2887 \\
\hline csigma & 2.000 & 1.3525 & 0.8765 & 1.7459 & gamma & 0.3750 \\
\hline ctheta & 0.700 & 0.5852 & 0.4222 & 0.8257 & beta & 0.1000 \\
\hline cchi & 2.000 & 2.4886 & 1.1941 & 3.6389 & gamma & 0.7500 \\
\hline czeta & 4.000 & 1.9989 & 0.6985 & 3.3205 & gamma & 1.5000 \\
\hline
\end{tabular}


The Chinese Economic Transformation

\begin{tabular}{|c|c|c|c|c|c|c|}
\hline & Prior mean & Post mean & $90 \% \mathrm{HPL}$ & erval & Prior & Pstdev \\
\hline ctau & 0.220 & 0.2622 & 0.0583 & 0.4580 & gamma & 0.1000 \\
\hline cphi & 0.250 & 0.0471 & 0.0092 & 0.0847 & beta & 0.1250 \\
\hline calpha & 0.600 & 0.3066 & 0.1694 & 0.4440 & beta & 0.1000 \\
\hline gammaw & 0.500 & 0.2939 & 0.1110 & 0.4658 & beta & 0.1500 \\
\hline xiw & 0.500 & 0.6172 & 0.5352 & 0.7205 & beta & 0.1000 \\
\hline gammap & 0.500 & 0.3015 & 0.1326 & 0.4820 & beta & 0.1500 \\
\hline xip & 0.500 & 0.7693 & 0.7071 & 0.8405 & beta & 0.1000 \\
\hline phir & 0.750 & 0.6478 & 0.5332 & 0.7714 & beta & 0.1000 \\
\hline phipi & 1.500 & 1.9313 & 1.5072 & 2.3432 & gamma & 0.2500 \\
\hline phiy & 0.125 & 0.0430 & 0.0195 & 0.0683 & gamma & 0.0500 \\
\hline phidy & 0.125 & 0.0963 & 0.0491 & 0.1404 & gamma & 0.0500 \\
\hline zstarss & 1.163 & 1.2358 & 1.0650 & 1.3767 & gamma & 0.1000 \\
\hline psiss & 0.077 & 0.0730 & 0.0163 & 0.1248 & gamma & 0.0400 \\
\hline hss & 0.000 & 1.4090 & -1.1566 & 4.3397 & norm & 2.0000 \\
\hline piss & 0.272 & 0.3744 & 0.1941 & 0.5288 & gamma & 0.1000 \\
\hline rnss & 1.030 & 1.0595 & 0.9096 & 1.2015 & gamma & 0.1000 \\
\hline eta & 0.973 & 0.9717 & 0.9504 & 0.9917 & beta & 0.0200 \\
\hline nkss & 0.500 & 0.4947 & 0.3934 & 0.5836 & beta & 0.0700 \\
\hline $\mathrm{cmu}$ & 0.070 & 0.0224 & 0.0142 & 0.0317 & gamma & 0.0200 \\
\hline ress & 1.242 & 1.2320 & 1.1524 & 1.3114 & gamma & 0.0500 \\
\hline rho_b & 0.500 & 0.6454 & 0.3053 & 0.9043 & beta & 0.2000 \\
\hline rho_g & 0.500 & 0.8943 & 0.8312 & 0.9641 & beta & 0.2000 \\
\hline rho_w & 0.500 & 0.3522 & 0.0732 & 0.6039 & beta & 0.2000 \\
\hline rho_p & 0.500 & 0.8405 & 0.7321 & 0.9461 & beta & 0.2000 \\
\hline rho_i & 0.500 & 0.7362 & 0.5906 & 0.9162 & beta & 0.2000 \\
\hline rho_r & 0.500 & 0.4865 & 0.2962 & 0.7321 & beta & 0.2000 \\
\hline rho_z & 0.500 & 0.1716 & 0.0348 & 0.2960 & beta & 0.2000 \\
\hline rho_psi & 0.500 & 0.9431 & 0.9056 & 0.9854 & beta & 0.2000 \\
\hline rho_nu & 0.500 & 0.9747 & 0.9545 & 0.9960 & beta & 0.2000 \\
\hline rho_mu & 0.500 & 0.8114 & 0.7099 & 0.9071 & beta & 0.2000 \\
\hline rho_eta & 0.500 & 0.7650 & 0.6124 & 0.9208 & beta & 0.2000 \\
\hline rho_mg & 0.500 & 0.2410 & 0.0441 & 0.4254 & beta & 0.2000 \\
\hline e_b & 0.500 & 6.0075 & 2.3428 & 11.7735 & invg & $\operatorname{lnf}$ \\
\hline e_g & 0.500 & 1.2548 & 0.8911 & 1.6161 & invg & $\operatorname{lnf}$ \\
\hline e_w & 0.500 & 0.5312 & 0.3542 & 0.7339 & invg & $\operatorname{lnf}$ \\
\hline e_p & 0.500 & 0.2457 & 0.1294 & 0.3331 & invg & $\operatorname{lnf}$ \\
\hline e_i & 0.500 & 0.8898 & 0.6847 & 1.1021 & invg & $\operatorname{lnf}$ \\
\hline e_r & 0.500 & 0.1507 & 0.1230 & 0.1822 & invg & $\operatorname{lnf}$ \\
\hline e_z & 0.500 & 2.1435 & 1.6746 & 2.6424 & invg & $\operatorname{lnf}$ \\
\hline
\end{tabular}


4. A structural investigation of the Chinese economy with a hybrid monetary policy rule

\begin{tabular}{|l|r|r|r|r|r|r|}
\hline & Prior mean & Post mean & \multicolumn{2}{|c|}{$90 \%$ HPD interval } & \multicolumn{1}{c|}{ Prior } & \multicolumn{1}{c|}{ Pstdev } \\
\hline e_psi & 0.500 & 0.4347 & 0.2928 & 0.5719 & invg & Inf \\
\hline e_nu & 0.500 & 3.4362 & 2.1762 & 4.4342 & invg & Inf \\
\hline e_mu & 0.500 & 0.1793 & 0.1365 & 0.2183 & invg & Inf \\
\hline e_eta & 0.500 & 1.2113 & 0.7844 & 1.6362 & invg & Inf \\
\hline e_mg & 0.500 & 0.4336 & 0.3271 & 0.5388 & invg & Inf \\
\hline
\end{tabular}

Note: Alpha is the weight on quantity rule.

Table A4.3 Prior and posterior distributions of parameters - subsample: after 2009Q1

\begin{tabular}{|c|c|c|c|c|c|c|}
\hline & Prior mean & Post mean & \multicolumn{2}{|c|}{ 90\% HPD interval } & Prior & Pstdev \\
\hline alpha & 0.500 & 0.2466 & 0.0046 & 0.5121 & unif & 0.2887 \\
\hline csigma & 2.000 & 1.0819 & 0.7355 & 1.3970 & gamma & 0.3750 \\
\hline ctheta & 0.700 & 0.6755 & 0.5693 & 0.7927 & beta & 0.1000 \\
\hline cchi & 2.000 & 2.2995 & 1.3164 & 3.3768 & gamma & 0.7500 \\
\hline czeta & 4.000 & 4.8390 & 3.2622 & 6.4291 & gamma & 1.5000 \\
\hline ctau & 0.220 & 0.2482 & 0.0801 & 0.4042 & gamma & 0.1000 \\
\hline cphi & 0.250 & 0.1240 & 0.0181 & 0.2228 & beta & 0.1250 \\
\hline calpha & 0.600 & 0.1712 & 0.1142 & 0.2296 & beta & 0.1000 \\
\hline gammaw & 0.500 & 0.4677 & 0.2475 & 0.6837 & beta & 0.1500 \\
\hline xiw & 0.500 & 0.6025 & 0.4935 & 0.7156 & beta & 0.1000 \\
\hline gammap & 0.500 & 0.5818 & 0.3744 & 0.7944 & beta & 0.1500 \\
\hline xip & 0.500 & 0.8019 & 0.7269 & 0.8755 & beta & 0.1000 \\
\hline phir & 0.750 & 0.8010 & 0.6807 & 0.9109 & beta & 0.1000 \\
\hline phipi & 1.500 & 1.6664 & 1.2879 & 2.0263 & gamma & 0.2500 \\
\hline phiy & 0.125 & 0.0794 & 0.0267 & 0.1376 & gamma & 0.0500 \\
\hline phidy & 0.125 & 0.1161 & 0.0576 & 0.1709 & gamma & 0.0500 \\
\hline zstarss & 1.163 & 1.1451 & 1.0167 & 1.2853 & gamma & 0.1000 \\
\hline psiss & 0.077 & 0.0763 & 0.0176 & 0.1353 & gamma & 0.0400 \\
\hline hss & 0.000 & -2.3959 & -4.5247 & -0.1487 & norm & 2.0000 \\
\hline piss & 0.272 & 0.2334 & 0.1023 & 0.3559 & gamma & 0.1000 \\
\hline rnss & 1.030 & 1.1051 & 0.9671 & 1.2318 & gamma & 0.1000 \\
\hline eta & 0.973 & 0.9292 & 0.8976 & 0.9599 & beta & 0.0200 \\
\hline nkss & 0.500 & 0.5809 & 0.4934 & 0.6743 & beta & 0.0700 \\
\hline $\mathrm{cmu}$ & 0.070 & 0.0336 & 0.0223 & 0.0446 & gamma & 0.0200 \\
\hline ress & 1.242 & 1.2259 & 1.1388 & 1.3026 & gamma & 0.0500 \\
\hline rho_b & 0.500 & 0.3179 & 0.0456 & 0.5699 & beta & 0.2000 \\
\hline rho_g & 0.500 & 0.9493 & 0.9213 & 0.9821 & beta & 0.2000 \\
\hline rho_w & 0.500 & 0.2446 & 0.0481 & 0.4495 & beta & 0.2000 \\
\hline rho_p & 0.500 & 0.8293 & 0.6927 & 0.9755 & beta & 0.2000 \\
\hline
\end{tabular}


The Chinese Economic Transformation

\begin{tabular}{|l|r|r|r|r|r|r|}
\hline & Prior mean & Post mean & \multicolumn{1}{|c|}{$90 \%$ HPD interval } & Prior & \multicolumn{1}{c|}{ Pstdev } \\
\hline rho_i & 0.500 & 0.8467 & 0.7585 & 0.9440 & beta & 0.2000 \\
\hline rho_r & 0.500 & 0.4587 & 0.1000 & 0.8045 & beta & 0.2000 \\
\hline rho_z & 0.500 & 0.1655 & 0.0381 & 0.2872 & beta & 0.2000 \\
\hline rho_psi & 0.500 & 0.9619 & 0.9374 & 0.9900 & beta & 0.2000 \\
\hline rho_nu & 0.500 & 0.9659 & 0.9472 & 0.9853 & beta & 0.2000 \\
\hline rho_mu & 0.500 & 0.2073 & 0.0559 & 0.3554 & beta & 0.2000 \\
\hline rho_eta & 0.500 & 0.5218 & 0.2850 & 0.7456 & beta & 0.2000 \\
\hline rho_mg & 0.500 & 0.3737 & 0.1227 & 0.6500 & beta & 0.2000 \\
\hline e_b & 0.500 & 1.8163 & 0.8817 & 2.7888 & invg & Inf \\
\hline e_g & 0.500 & 0.7046 & 0.5510 & 0.8704 & invg & Inf \\
\hline e_w & 0.500 & 0.3571 & 0.2584 & 0.4449 & invg & Inf \\
\hline e_p & 0.500 & 0.1899 & 0.1141 & 0.2564 & invg & Inf \\
\hline e_i & 0.500 & 1.2825 & 0.9970 & 1.5376 & invg & Inf \\
\hline e_r & 0.500 & 0.1086 & 0.0855 & 0.1322 & invg & Inf \\
\hline e_z & 0.500 & 1.7497 & 1.2774 & 2.2522 & invg & Inf \\
\hline e_psi & 0.500 & 0.2778 & 0.1801 & 0.3815 & invg & Inf \\
\hline e_nu & 0.500 & 3.4748 & 2.6189 & 4.3040 & invg & Inf \\
\hline e_mu & 0.500 & 0.3267 & 0.2609 & 0.3989 & invg & Inf \\
\hline e_eta & 0.500 & 0.8334 & 0.5687 & 1.1040 & invg & Inf \\
\hline e_mg & 0.500 & 0.7029 & 0.5697 & 0.8478 & invg & Inf \\
\hline
\end{tabular}

Note: Alpha is the weight on quantity rule.

Table A4.4 Forecast error decompositions of the variances of output, consumption, investment and loans

\begin{tabular}{|c|c|c|c|c|c|c|c|c|c|}
\hline & & \multicolumn{2}{|c|}{ Output } & \multicolumn{2}{|c|}{ Consumption } & \multicolumn{2}{|c|}{ Investment } & \multicolumn{2}{|l|}{ Loan } \\
\hline & & $\mathrm{T}=8$ & $\mathrm{~T}=32$ & $\mathrm{~T}=8$ & $\mathrm{~T}=32$ & $\mathrm{~T}=8$ & $\mathrm{~T}=32$ & $\mathrm{~T}=8$ & $\mathrm{~T}=32$ \\
\hline$z^{b}$ & Preference & 23.78 & 21.85 & 69.44 & 68.13 & 0.02 & 0.02 & 0.05 & 0.04 \\
\hline$z^{g}$ & Exogenous demand & 34.84 & 32.37 & 0.61 & 0.63 & 0.33 & 0.27 & 0.02 & 0.03 \\
\hline$z^{w}$ & Wage & 0.01 & 0.01 & 0.03 & 0.03 & 0.04 & 0.03 & 0.05 & 0.04 \\
\hline$z^{p}$ & $\begin{array}{l}\text { Intermediate-good price } \\
\text { markup }\end{array}$ & 4.42 & 5.01 & 2.85 & 3.12 & 6.85 & 5.74 & 5.59 & 4.5 \\
\hline$z^{i}$ & Investment-good price markup & 0.15 & 0.18 & 0 & 0 & 0.87 & 0.7 & 0.21 & 0.24 \\
\hline$z^{z}$ & Neutral technology & 23.94 & 22.43 & 23.37 & 23.4 & 1.42 & 1.26 & 1.15 & 1.78 \\
\hline$z^{\psi}$ & IS technology & 6.09 & 11.08 & 2.2 & 2.48 & 50.15 & 61.28 & 51.78 & 55.21 \\
\hline$z^{\nu}$ & MEI & 2.49 & 2.51 & 0.26 & 0.62 & 11.8 & 9.4 & 8.45 & 10.12 \\
\hline$z^{\mu}$ & EF premium & 0.12 & 0.12 & 0 & 0 & 0.73 & 0.48 & 1.07 & 0.82 \\
\hline$z^{\eta}$ & Net worth & 3.16 & 3.44 & 0.63 & 0.96 & 26.05 & 19.6 & 30.05 & 25.96 \\
\hline$z^{m}$ & Real money growth & 0 & 0 & 0 & 0 & 0 & 0 & 0 & 0 \\
\hline$z^{r}$ & Hybrid monetary policy & 0.55 & 0.52 & 0.29 & 0.28 & 1.09 & 0.72 & 1.48 & 1.13 \\
\hline$z^{m g}$ & Quantitative monetary policy & 0.46 & 0.49 & 0.33 & 0.34 & 0.66 & 0.52 & 0.1 & 0.13 \\
\hline
\end{tabular}


4. A structural investigation of the Chinese economy with a hybrid monetary policy rule
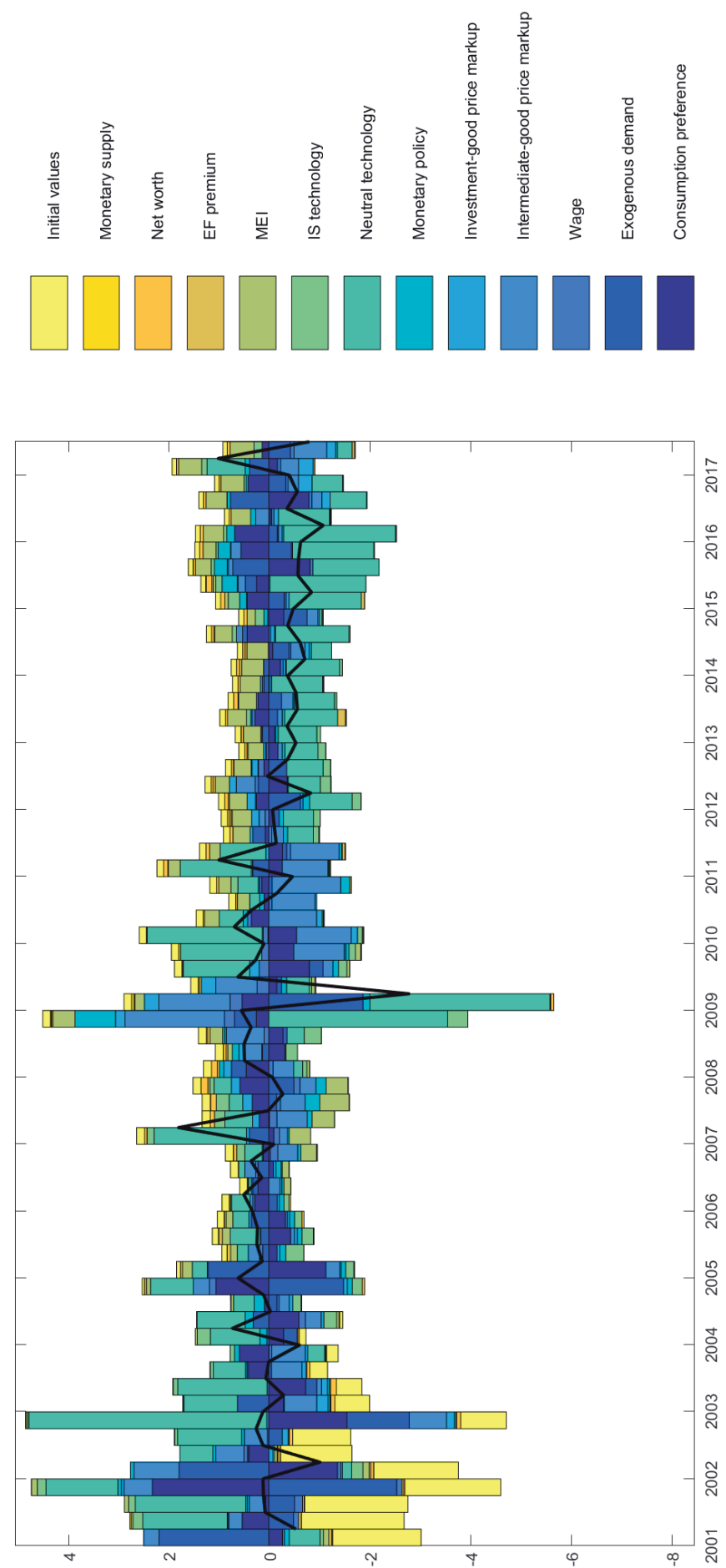

Figure A4.1 Historical decompositions of output 

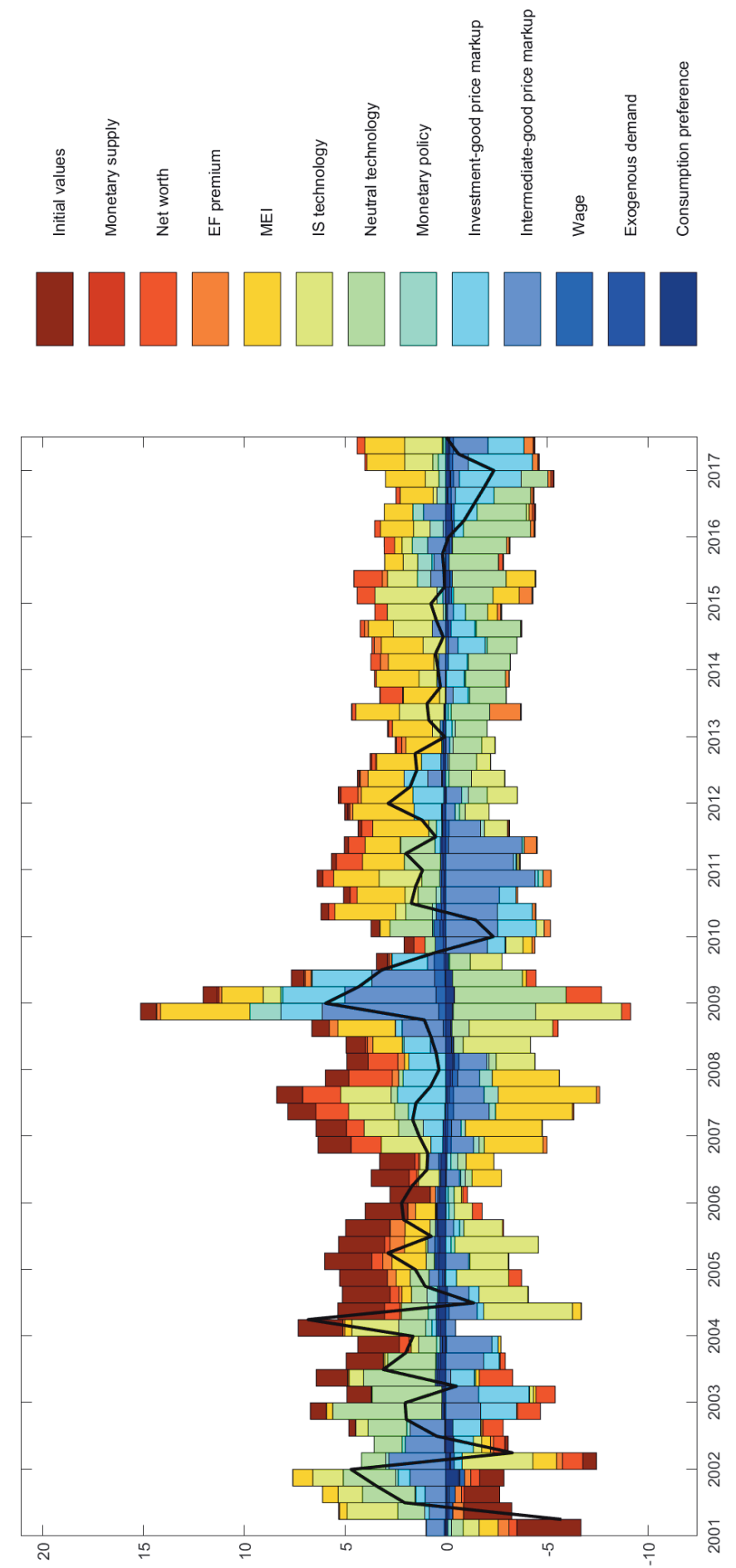

Figure A4.2 Historical decompositions of investment 
This text is taken from The Chinese Economic Transformation: Views from Young Economists, edited by Ligang Song, Yixiao Zhou and Luke Hurst, published 2019 by ANU Press, The Australian National University, Canberra, Australia.

doi.org/10.22459/CET.2019.04 